CORRECTION

\title{
Correction: Assigning the right credit to the wrong action: compulsivity in the general population is associated with augmented outcome-irrelevant value-based learning
}

Nitzan Shahar (D), Tobias U. Hauser (D), Rani Moran, Michael Moutoussis, NSPN consortium*, Edward T. Bullmore (iD) and Raymond J. Dolan (iD

(c) The Author(s) 2021

Translational Psychiatry (2021)11:610; https://doi.org/10.1038/s41398-021-01734-8

Correction to: Translational Psychiatry https://doi.org/10.1038/ s41398-021-01642-x, published online 5 November 2021

The original version of this article unfortunately contained a few minor mistakes in the references generated during an automated proofing process and a typo in Figure 1 (instead of PADWA it should say PADUA). We apologize for the errors. The original article has been corrected.

\begin{abstract}
(c) Open Access This article is licensed under a Creative Commons Attribution 4.0 International License, which permits use, sharing, adaptation, distribution and reproduction in any medium or format, as long as you give appropriate credit to the original author(s) and the source, provide a link to the Creative Commons license, and indicate if changes were made. The images or other third party material in this article are included in the article's Creative Commons license, unless indicated otherwise in a credit line to the material. If material is not included in the article's Creative Commons license and your intended use is not permitted by statutory regulation or exceeds the permitted use, you will need to obtain permission directly from the copyright holder. To view a copy of this license, visit http://creativecommons. org/licenses/by/4.0/.
\end{abstract}

(๑) The Author(s) 2021 